\title{
Power Efficient Two Transistor Exclusiveor Gate for Full Adder Usinggdi in 45NM
}

\author{
J Nageswara Reddy a, Dr. Mukesh Tiwari ${ }^{\text {b }}$ and Dr. Vundela Padmanabha Reddy \\ ${ }^{a}$ Research Scholar, Dept. of Electronics and Communication Engineering, \\ Sri Satya Sai University of Technology \& Medical Sciences, Sehore, Bhopal Indore Road, Madhya Pradesh, India \\ ${ }^{\mathbf{b}}$ Research Guide, Dept. of Electronics and Communication Engineering, \\ Sri Satya Sai University of Technology \& Medical Sciences, Sehore, Bhopal Indore Road, Madhya Pradesh, India \\ ${ }^{c}$ RESEARCH Co-Guide Department of ECE, Institute of Aeronautical Engineering, Hyderabad
}

Article History: Received: 11 January 2021; Accepted: 27 February 2021; Published online: 5 April 2021

\begin{abstract}
The principle part of ALU (Arithmetic rationale unit) is the Full Adder. This paper tells the best way to perform quick arithmetic activities created utilizing GDI. The fundamental point of this paper is to plan the full adder of two semiconductor utilizing Gate diffusion input (GDI) strategy. The plan of full adder is appropriate for the two semiconductor EX-OR gate. The primary intension of novel technique is fully founded on Full adder plan of 2TEX OR gate which is utilized to decrease power and improve the speed with an advanced territory of number of semiconductor check which is less similar with CMOS innovation. The best strategy for GDI is to plan advanced rationale circuits and which will in general improve the conditions.GDI system is functional to Full adder plan. The Cadence apparatus is to figure power, postponement and region for two semiconductor EX-OR gate. The total work is done in $45 \mathrm{~nm}$ innovation. The investigation of the outcomes show that the planned strategy is superior to traditional CMOS innovation.
\end{abstract}

\section{Key words: CADENCE Tool,CMOS,GDI,EX-OR}

\section{Introduction}

The current days of the circuit multifaceted nature the quantity of semiconductors are implanted on a chip. The gadgets are portrayed by different variables like power utilization, speed and region. The significant issues in exceptionally enormous scope mix plan (VLSI) are speed, zone and power utilization. The principle focus in VLSI are increment the semiconductor rely on a chip which prompts expanded the temperature of the IC and power utilization. It influences the battery strength in compact gadgets. There are three sorts of power utilization in COMS VLSI. They are

1. First one-When semiconductor is in off express, the power utilization is because of undesirable spillage current.

2. Second one-The energeticcontrol utilizationfor the reason that of the exchanging freeloading segments.

3.Third one-The short out power utilization is because of variety of current between $V_{d d}$ to $V_{s s}$

Till now the rationale strategy in standard static is the plan of full adder. The rationale strategies in the customary full adder are the, pass semiconductor, transmission gate and CMOS circuit.

The preferences having CMOS innovation by utilizing pass semiconductor rationale (PTL). The fundamental inconvenience of the pass semiconductor rationale are the limit drop. The aftereffects of every semiconductors diminish the sink and source current. It prompts diminish working pace at low stockpile voltage and high input voltage at changing inverters isn't in $\mathrm{V}_{\mathrm{dd}}$. Perhaps the most significant in Full adder of 10 semiconductor has the issue of twofold limit misfortune, the plan of rapid and low power. The primary issue in static power dispersal happens in PMOS semiconductor in inverter (which isn't in fully off condition). The proposed technique is actualized for low power computerized circuit configuration is known as GDI.

The subject with planned strategy is the planning of a $90 \mathrm{~nm}$ full power adder with low power and two EX-OR semiconductor gates using GDI. The next segment clarifies quickly about the fundamental GDI innovation. The third Section portrays the customary strategy for full adder. The fourth part examines about the projected strategy for 2T EXOR base of full adder planned with 6T semiconductor utilizing GDI method.

\section{GATE DIFFUSION INPUT}

GDI is the innovative method for advanced combinatorial circuits with low power consumption. It generally speeds up, lessens the power utilization and region of the advanced combinational circuits and it keep up the low unpredictability of the rationale circuit plan.

The straightforward essential GDI cell as appeared in figure1. The Gate Diffusion Input cell has 3 inputs.

$\mathrm{P}$ is the channel for $\mathrm{pMOS}$ or source for the input and

$\mathrm{N}$ is the input for nMOS source or exhaust,

$\mathrm{G}$ is for regular input gate for pMOS\& nMOS.

Different data sources could be related to G, P and N connectors. Differentiated and COMS methodology: The GDI system contains less silicon area due to lower semiconductor numbers, and since the area occupancy is less, the capacity of the central point is lower. They all recommend a higher speed of operation, which shows that the GDI reasoning system is a beneficial technique for planning an adder. 


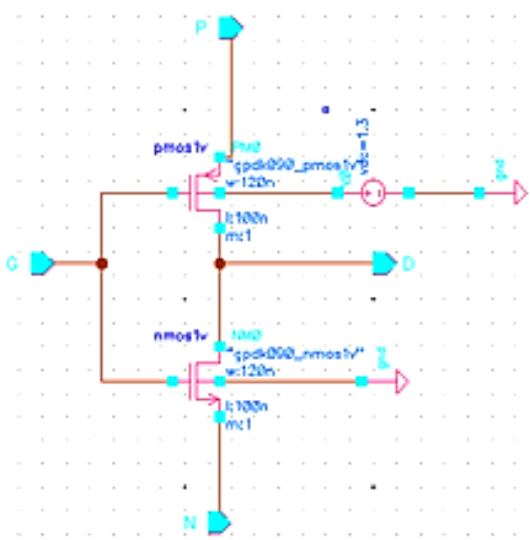

Fig.1. Basic GDI cell

The edge voltage depends on a requirement for the ground voltage. The ground connection of pMOS and nMOS must be related to their flux in order to limit the mass effect. The range to the edge as a result of the progression of the VSB is called the leveling of the body. The direct tilt of the body shows the influence of the cut-off voltage when it is not tied to a base.

\section{T CMOSFULL ADDER}

The following circuit is a full adder arranged at $8 \mathrm{~T}$ with data sources $\mathrm{C}$, A and B producing Cout and SUM. In this article, the full adder is organized with a gate 2: 1 Mux and 2EXOR. The absolute value of the power of the following EXOR input is obtained and the step is generated by the power of the multiplexers, as shown in Fig 2.

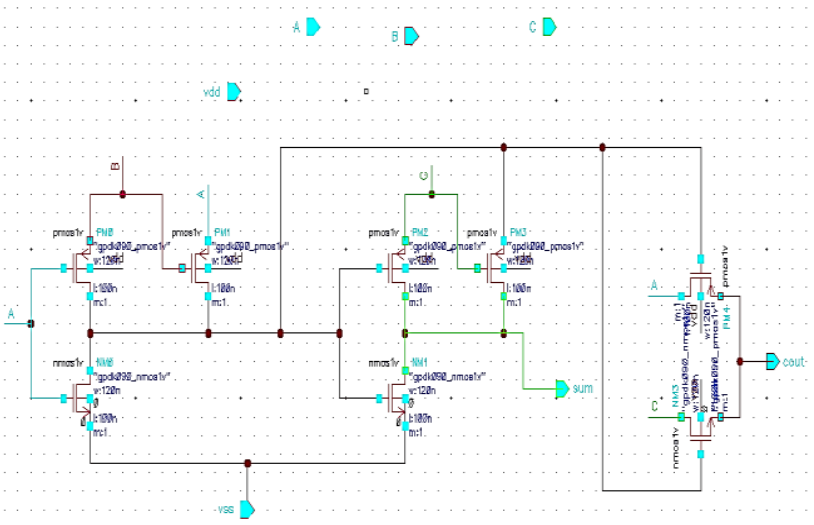

Fig.2. Full adder design of CMOS

\section{T FULL ADDER}

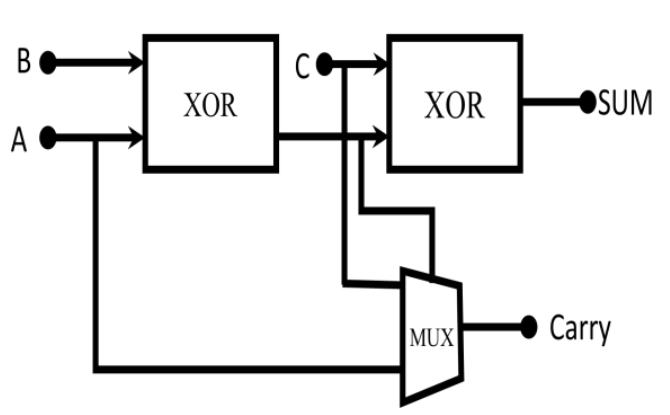

Fig.3. Full adder block diagram

The presentation of the full adder circuit can be clarified now as follow: The expansion of two single piece input $\mathrm{A}, \mathrm{B}$ with input convey $\mathrm{C}_{\text {in }}$ provide the two single piece yields do $\mathrm{C}_{\text {out. }}$ and $\mathrm{Sum}$.

Where

Sum $=\mathrm{A} \square \mathrm{B} \square \mathrm{C}(1)$

Carry=A.B+(A $\square \mathrm{B}) \cdot \mathrm{C}(2)$

The XOR gate configuration should contain less semiconductor data for low force dispersion. The reason for adopting the multiplexer circuit in our organized configuration is to provide a cost. The transmit input is used as a multiplexer as it speeds up the transmission and increases the output voltage as a level recovery circuit. The 
entire arranged adder circuit requires a multiplexer and two XOR inputs, it only requires 6 semiconductors. Table 1 explains the utility method of the full adder. The normal technique for accumulating a full adder using the multiplexer and the XOR inputs as shown in Fig 3. The multiplexer and the XOR gate are two basic parts in full adder circuitry. The intelligent and arithmetic exercises of the full adder are fully defined in the squares of the multiplexer and the XOR input.

Table.1. Full adder Truth table

\begin{tabular}{|c|c|c|c|c|}
\hline $\boldsymbol{A}$ & $\boldsymbol{B}$ & $\boldsymbol{C}_{\text {in }}$ & SUM & Carry \\
\hline 0 & 0 & 0 & 0 & 0 \\
\hline 0 & 0 & 1 & 1 & 0 \\
\hline 0 & 1 & 0 & 1 & 0 \\
\hline 0 & 1 & 1 & 0 & 1 \\
\hline 1 & 0 & 0 & 1 & 0 \\
\hline 1 & 0 & 1 & 0 & 1 \\
\hline 1 & 1 & 0 & 0 & 1 \\
\hline 1 & 1 & 1 & 1 & 1 \\
\hline
\end{tabular}

Fig.4.XOR gate of $2 \mathrm{~T}$

In fig.4. The gate of X-OR arrangement using GDI technology has nMOS \& pMOS semiconductors with inputs A, B. If these are established, nMOS will be OFF and pMOS will be low ON, so performance will be poor. Exactly when the nMOS is on, input A is low and B is high, pMOS state is off, so Abdank is high, when B is low and $\mathrm{A}$ is high, the state of nMOS is on and pMOS is off, i.e. the Efficiency is high, when the two sources of information are high the power is low so the above circuit works as an gate of X-OR. 


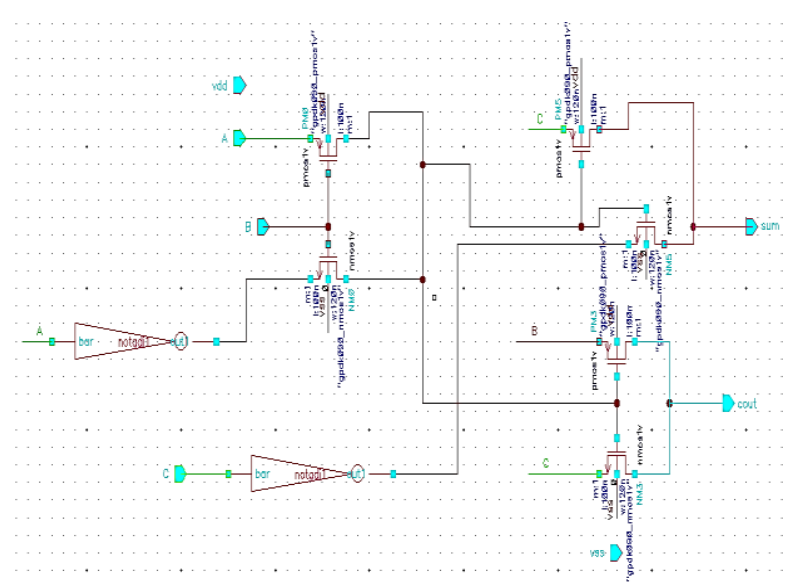

Fig.5. Design of proposed Full Adder

One OR gate and two AND gates of available full adder replaced with the multiplexer in arranged circuit. Here yield of first XOR gate is spread over to the gate terminal of M6 and M5, input B is related with channel of M6, input Cin is related with wellspring of M5, multiplexer produce Cout.The fig.5.show to arranged full adder circuit with 6 semiconductors, for instance, M6, M5, M4, M3, M2 and M1. M2 and M1 semiconductors go probably as first gateof XOR, input Arelated with channel of M2, Abar is related with wellspring of Band M1 is related at gate station of M2 \& M1. M4and M3 goes probably as second XOR gate, input Cin is related with channel of M4, Cinbar is related with wellspring of M3 and yield of first XOR gate apply as contribution to the gate terminals of M4 and M3, the second XOR gate yield SUM as yield.

\section{RESULT AND DISCUSSION}

In table 2, thedevelopment in power and defer examination in $45 \mathrm{~nm}$ innovation of proposed framework over the customary technique. The thought of zone shows the quantity of semiconductor check is less nearly with the regular CMOS method. On the off chance that amount of semiconductors is diminished, the unpredictability of the circuit will diminish, velocity will increment and use of power will decrease. Fig6. Display the circumstance deferrals and power examination which is classified. In proposed strategy power decreases up to $32 \%$ deferral lessens up to $10 \%$ contrast and ordinary CMOS Full adder. Time postponement and power determined utilizing in rhythm apparatus.

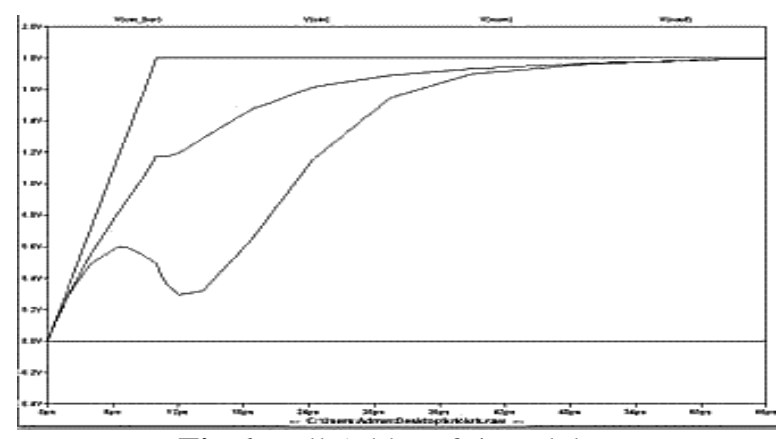

Fig.6. Full Adder of time delay

In fig 6, it displays the delay-time cause of various load transformation related with nMOS and pMOS devices.

Table 2. Comparison table 


\begin{tabular}{|c|c|c|c|c|c|c|}
\hline $\begin{array}{c}\text { Adder } \\
\text { style }\end{array}$ & $\begin{array}{c}\text { Area } \\
\text { (transisto } \\
\text { r count) }\end{array}$ & Power(w) & $\begin{array}{c}\text { Time } \\
\text { delay(sec.) }\end{array}$ & $\begin{array}{c}\text { Area } \\
\text { (transisto } \\
\text { r count) }\end{array}$ & Power(w) & $\begin{array}{c}\text { Time } \\
\text { delay(sec.) }\end{array}$ \\
\hline Not & 2 & $\begin{array}{c}166.2 \times 10 \\
-9\end{array}$ & $235 \times 10^{-12}$ & 2 & $13.1 \times 10^{-9}$ & $\begin{array}{c}201.8 \times 10^{-} \\
12\end{array}$ \\
\hline EXOR & 8 & $\begin{array}{c}388.6 \times 10 \\
-9\end{array}$ & $\begin{array}{c}168 \times 10^{-9} \\
\text { CMOS 90nm }\end{array}$ & 2 & $\begin{array}{c}40.47 \times 10^{-} \\
9\end{array}$ & $20.07 \times 10^{-9}$ \\
\hline $\begin{array}{c}\text { Fu11 } \\
\text { Adder }\end{array}$ & 8 & $\begin{array}{c}592.3 \times 10 \\
-9\end{array}$ & $\begin{array}{c}50.14 \times 10^{-} \\
9\end{array}$ & 6 & $\begin{array}{c}146.9 \times 10^{-} \\
9\end{array}$ & $30.03 \times 10^{-9}$ \\
\hline
\end{tabular}

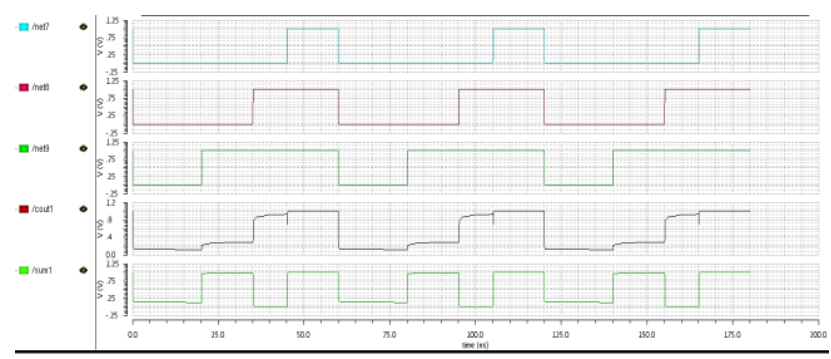

Fig.7. Planned 6T full adder of Transient response

\section{CONCLUSION}

The planned full adder planned utilizing 90nm has improved execution as far as region, postponement and power utilization contrasted and customary full adder. Plan multifaceted nature is additionally diminished when utilized GDI technique.Considering every one of these variables, the proposed procedure can likewise be utilized to plan combinational and successive circuits.

\section{References}

1. AbeyJoji, "Mutual Fund: Investors Perception on Investment", International Journal of Sciences: Basic and Applied Research (IJSBAR), Volume 34, No. 3, Pp. 55-67, ISSN 2307 - 4531, 2017.

2. Agarwal Shivangi and MirzaNawazish, "A Study on the Risk-Adjusted Performance of Mutual Fund Industry in India", Review of Innovation and Competitiveness, Vol. 3, Issue 1, 2017

3. Agrawal Gaurav and Jain Mini, "Investor's Preference towards Mutual Fund in Comparison to other Investment Avenues", Journal of Indian Research, ISSN: 2321 - 4155, Vol. 1, No. 4, Pp - 115 -131, October - December 2013.

4. Alamelu. K. and Indhumathi. G., “Analysis of Sip Investments of Mutual Funds In India”, International Journal of Economic Research, Vol. 14, ISSN: 0972-9380, Available at Http: www. SerialJournal.Com, Nov. 2017

5. Anis Ali and BajpaiSaurabh, "Risk Opportunities and Returns for Investors in Mutual Fund", International Journal of Technology Management and Humanities, Vol.1, Issue 4, ISSN. 2454-566x, March 2016

6. Aratrika Deb, "Asset Management Companies and Their Growing Importance in the Field of Investment”, Corporate Law Reporter.Com, The Daily Journal, 17 March 2015

7. BaliyanMeenu and RathiPunjika, "Performance Evaluation of Emerging Mutual Fund", Scientific Society of Advanced Research and Social Change (SSARSC) International Journal of Management, Vol. 3, Issue 1, ISSN 2349 - 6975, , Jan - June 2017.

8. Bandi Swati “The Mutual Fund Industry: A View of Agents and Advisors on Micro Sip's (Systematic Investment Plan)", International Journal of Engineering Technology Science and Research (IJETSR), Vol. 4, Issue 9, ISSN: 2394-3386, Sep 2017.

9. Banerjee Sudip, and GoyalMeenu, "Performance and Prospects of Mutual Funds With Special Reference To Large Capital Equity Oriented Schemes", Abhinav National Monthly Referred Journal of Research in Commerce and Management, Vol.6, Issue 8, ISSN.: 2277-1166, August 2017.

10. Bansal Sandeep, “Investors Perception Regarding Mutual Fund and Other Investment Tools”, Journal of International Academic Research for Multidisciplinary, Impact Factor 1.393, ISSN: 2320 - 5083, Volume 2, Issue 5, June 2014 
11. Vengatesan, K. et al. "Secure Data Transmission Through Steganography with Blowfish Algorithm". Lecture Notes on Data Engineering and Communications Technologies 35. (2020): 568-575.

12. Chalamet. al "Demographic Variables Influencing In the Retail Investors Investment". Abhinav International Monthly Refereed Journal of Research in Management and Technology, Vol.II, 131-138, Nov. 2014

13. Chauhan Pratap M. and Adhav Sunil M., "Recent Trends in Mutual Fund Industry in India", International Journal of Science, Technology Management, Volume No.4, Issue No.4, and ISSN: 2394 -1537, April 2015.

14. Et Bureau, "How to Choose A Mutual Fund Distributors, by Prashant Mahesh, 12th Oct 2017

15. Gandhi R. Kumar and Perumal R., "Mutual Fund Financial Performance Analysis - A Comparative Study on Equity Diversified Schemes and Equity mid Cap Schemes", AMET International Journal of Management, ISSN 2231-6779, Jan - June 2015

16. George Deepthi and ChandranJagadees, "A Study on Women's Preference towards Mutual Fund Investment with Special Reference to Cochin", IOSR Journal of Humanities and Social Sciences (IOSR JHSS), Volume 21, Issue 7, Version VII, Pp. 23-28, ISSN: 2279-0837, July 2016

17. GodaseSaudagar and SenguptaSuchismitaa, "Long-Term Performance of EquityBased Mutual Fund (Systematic Investment Plan)", Twelfth Aims International Conference on Management, ISBN: 978-81924713-8-9, 2015

18. Jacob Tom and Kattookaran Thomas Paul, " Comparative Study of the Mutual Fund Schemes of Reliance and Unit Trust of India", IRC's International Journal of Multidisciplinary Research in Social and Management Sciences, Vol.2, Issue 3, ISSN: 2320 - 8236, July - Sep 2014

19. Kanodia Monty and KhinchiKiran," Performance Evaluation of Mutual Funds in India: Literature Review", Everant.Org/Afmj, Account and Financial Management Journal, Vol.2, Issue 09, ISSN: 24563374, Impact Factor: 4.614, DOI: 10.18535/Afmj/V2i9.02, Sep 2017 